\title{
EVALUASI LAHAN UNTUK PENGEMBANGAN LAHAN PERKEBUNAN DI PULAU BACAN KABUPATEN HALMAHERA SELATAN
}

\author{
Sitti Wakiah \\ Johan A. Rombang \\ Johannes E.X. Rogi
}

\begin{abstract}
The research objective was to determine the suitability of land for a certain class of agricultural crops, namely, vanilla, oil palm, coconut, cocoa, nutmeg and cloves and to determine the direction of the crop land use. The study used survey method and analysis is to compare with criteria data suitability of land for plantation crops. Based on the results obtained twenty eight overlay land units and land units nineteen taken as a sample. The results show the suitability of land in Bacan Island of South Halmahera District for commodity crop plantations vanilla, oil palm, coconut, nutmeg and cloves in a class of land suitability is quite suitable (S2), cocoa belongs to a class of land suitability is marginally suitable (S3) with limiting factor the relative humidity. Economic analysis for all commodities is very suitable for development and Bacan Island of South Halmahera Regency.
\end{abstract}

Keywords: Evaluation of Land Suitability, agricultural crops, land use planning, Bacan Island of South Halmahera Discrict

\begin{abstract}
ABSTRAK
Tujuan penelitian adalah untuk mengetahui kelas kesesuaian lahan untuk beberapa jenis tanaman perkebunan yaitu, vanili, kelapa sawit, kelapa, kakao, pala dan cengkeh dan untuk menentukan arahan penggunaan lahan tanaman tersebut.Penelitian menggunakan metode survei dan analisisnya adalah membandingkan (Matching) dengan data kriteria kesesuaian lahan untuk tanaman perkebunan. Berdasarkan hasil overlay diperoleh dua puluh delapan satuan lahan dan diambil sembilan belas satuan lahan sebagai sampel. Hasil penelitian menunjukkan kesesuaian lahan di Pulau Bacan Kabupaten Halmahera Selatan untuk komoditas perkebunan tanaman panili, kelapa sawit, kelapa, pala dan cengkeh termasuk dalam kelas kesesuaian lahan cukup sesuai (S2), kakao termasuk dalam kelas kesesuaian lahan sesuai marginal (S3) dengan faktor pembatas pada kelembaban nisbi. Analisa ekonomi untuk seluruh komoditas perkebunan tersebut sangat sesuai untuk dikembangkan dan di Pulau Bacan Kabupaten Halmahera Selatan.
\end{abstract}

Kata Kunci: Evaluasi Kesesuaian Lahan, Tanaman Perkebunan, Perencanaan Penggunaan Lahan, Pulau Bacan, Kabupaten Halmahera Selatan

\section{PENDAHULUAN}

Salah satu sub sektor dari sektor pertanian adalah sub sektor perkebunan. Sub sektor ini memberikan sumbangan yang cukup besar bagi perekonomian nasional dan menjadi makin penting peting, mengingat makin terbatasnya peranan minyak bumi yang selama ini merupakan sumber devisa utama bagi Indonesia. Keunggulan komparatif dari sub sektor perkebunan dibandingkan dengan sektor non migas lainya disebabkan antara lain oleh adanya lahan yang belum dimanfaatkan secara optimal dan berada dikawasan dengan iklim yang menunjang serta adanya tenaga kerja yang cukup tersedia dan melimpah sehingga secara kompetitif dapat dimanfaatkan.

Pengembangan tanaman perkebunan baik secara kualitas maupun kuantitas masih sangat dimungkinkan, terutama pengembangan dari sisi jumlah lahan produksi untuk menghasilkan informasi spasial kesesuaian lahan tersebut, diperlukan identifikasi dan evaluasi potensi sumberdaya lahan. 
Evaluasi lahan adalah proses penaksiran perilaku sumberdaya lahan apabila dipergunakan untuk maksud-maksud tertentu, termasuk pelaksanaan survei dan interpretasi serta studi bentuk lahan, tanah, vegetasi, iklim, beserta aspekaspek lain untuk menentukan dan membantu suatu perbandingan terhadap kemungkinan berbagai penggunaan lahan yang dapat diterapkan untuk berbagai pilihan penggunaan tertentu (FAO, 1976).Adanya keragaman sifat-sifat tanah, topografi dan iklim dapat digunakan sebagai dasar pemilihan berbagai komoditas yang sesuai untuk dikembangkan di suatu wilayah.

\section{METODE PENELITIAN}

Penelitian ini dilaksanakan selama 6 bulan (Januari- Juni 2015) di Pulau Bacan KabupatenHalmahera Selatan Propinsi Maluku Utara. Pemilihan lokasi penelitian dilakukan secara sengaja (purposive sampling). Adapun alat yang digunakan dalam penelitian ini kompas untuk menentukan arah, GPS, dan alat penggali profil tanah Bahan-bahan penelitian terdiri dari peta agroklimat / sebaran curah hujan dan data iklim, peta kawasan Hutan serta perubahan fungsi dan status kawasan, peta rencana tata ruang daerah Tingkat II dari Bappeda, peta kelas kelerengan, peta tanah, peta penggunaan lahan di wilayah pulau Bacan Kabupaten Halmahera Selatan. Pelaksanaan penelitian meliputi beberapa tahap kegiatan yaitu persiapan, penyusunan peta satuan lahan dan pengambilan contoh tanah.Analisis spasial yang dilakukan pada tahap ini adalah tumpang tindih (overlay) peta-peta dasar dan analisa contoh tanah di laboratorium.

Analisa data terdiri dari Analisis sampel tanah meliputi penetapan sifat fisik dan kimia, yaitu penetapan tekstur 3 fraksi (pasir, debu dan liat), kandungan bahan organik $(\mathrm{C}, \mathrm{N}$ dan $\mathrm{C} / \mathrm{N})$, reaksi tanah $\left(\mathrm{pH} \mathrm{H}_{2} \mathrm{O}\right)$, Kapasitas Tukar Kation, Kejenuhan Basa dan Salinitas dan analisis finansial usahatani yang digunakan untuk mengukur tingkat kelayakan usaha dari pola tanam yang diupayakan dengan menggunakan :

(1) Net present value (NPV)

(2) Benefit cost ratio (BCR)

(3) Discounted Cash Flow

(4) Internal Rate of Return (IRR).

Sedangkan NPV dan IRR untuk kelayakan usaha kelompok tanaman keras yang multi years, seperti tanaman tahunan dari kelompok komoditas perkebunan.

\section{HASIL DAN PEMBAHASAN}

\section{Karakteristik Lahan}

Karakteristik lahan yang diperoleh dari hasil overlay pada 3 Kecamatan di Pulau Bacan Kabupaten Halmahera Selatan, dapat dilihat padaTabel 1.

Tabel 1. Unit Lahan Kecamatan Bacan, Bacan Timur Tengah dan Bacan Selatan Kabupaten Halmahera Selatan

\begin{tabular}{ccccc}
\hline Kecamatan & Unit Lahan & Jenis Tanah & Kelerengan & Penggunaan Lahan \\
\hline \multirow{3}{*}{ Bacan } & 1 & Dystropepts & $0-2 \%$ & Hutan \\
& 3 & Tropaquepts & $0-2 \%$ & Hutan \\
& 11 & Dystropepts & $0-2 \%$ & Pertanian \\
& 15 & Dystropepts & $15-40 \%$ & Pertanian \\
& 19 & Dystropepts & $2-15 \%$ & Semak Belukar \\
& 22 & Dystropepts & $0-2 \%$ & Semak Belukar \\
Bacan Timur Tengah & 24 & Hydraquents & $0-2 \%$ & Semak Belukar \\
& 26 & Dystropepts & $15-40 \%$ & Hutan \\
& 5 & Dystropepts & $15-40 \%$ & Hutan \\
& 8 & Dystropepts & $2-15 \%$ & Pertanian \\
& 9 & Humitropepts & $2-15 \%$ & Pertanian \\
& 16 & Humitropepts & $15-40 \%$ & Pertanian \\
& 20 & Humitropepts & $2-15 \%$ & Pertanian \\
& 12 & Humitropepts & $0-2 \%$ & Pertanian \\
& 13 & Hydraquents & $0-2 \%$ & Pertanian \\
& 14 & Tropaquepts & $0-2 \%$ & Semak Belukar \\
\hline
\end{tabular}

Sumber: Data olahan (2015) 


\section{Analisa Kesesuaian Lahan}

Evaluasi kesesuaian lahan adalah proses penilaian terhadap sumberdaya lahan untuk tujuan tertentu dengan menggunakan suatu pendekatan atau cara yang sudah teruji. Hasilnya berupa arahan dan informasi tentang penggunaan lahan yang tepat sesuai dengan kondisi lahan yang ada.

Evaluasi kesesuaian lahan untuk tanaman perkebunan khususnya tanaman panili, kelapa sawit, kelapa, kakao, pala dan cengkeh di Pulau Bacan Kabupaten Halmahera Selatan didasarkan pada karateristik lahan yang telah dijelaskan sebelumnya, terhadap syarat tumbuh tanaman yang dimiliki.

Berdasarkan karateristik lahan tersebut selanjutnya dilakukan pengklasifikasian tingkat kelas kesesuaian lahan. Analisis data yangdigunakan yaitu metode membandingkan (Matching) antara karateristik lahan dengan syarat tumbuh tanaman.Nilai terendah sebagai faktor pembatas evaluasi kesesuaian lahan. Faktor pembatas yang dimaksud adalah temperatur/suhu (tc), ketersediaan air (wa), ketersediaan oksigen (oa), media perakaran (rc), ketersediaan hara (nr) yang terdiri dari Kapasitas tukar kation (nr-1), kejenuhan basa (nr-2), $\mathrm{pH} \mathrm{H}_{2} \mathrm{O}$ (nr-3), C Organik (nr-4), bahaya erosi (eh) dan penyiapan lahan (lp).

Hasil membandingkan (Matching) tersebut, kemudian akan diklasifikasi dalam kelas sangat sesuai (S1), cukup sesuai (S2), sesuai marginal (S3) dan tidak sesuai (N) bagi pengembangan tanaman panili, kelapa sawit, kelapa, kakao, pala dan cengkeh. Lebih jelasnya tersaji pada Tabel. 2.

Tabel 2. Faktor Pembatas Kesesuaian Lahan Untuk Tanaman Vanili, KelapaSawit, Kelapa, Kakao, Pala dan Cengkeh.

\begin{tabular}{|c|c|c|c|c|c|c|c|c|c|c|c|c|}
\hline Parameter & \multicolumn{12}{|c|}{ KOMODITAS } \\
\hline $\begin{array}{l}\text { Persyarataan } \\
\text { Penggunaan/ }\end{array}$ & \multicolumn{2}{|c|}{ Panili } & \multicolumn{2}{|c|}{ Kelapa Sawit } & \multicolumn{2}{|c|}{ Kelapa } & \multicolumn{2}{|c|}{ Kakao } & \multicolumn{2}{|c|}{ Pala } & \multicolumn{2}{|c|}{ Cengkeh } \\
\hline & Nilai & Kls & Nilai & Kls & Nilai & Kls & Nilai & Kls & Nilai & Kls & Nilai & $\mathrm{Kls}$ \\
\hline Suhu(tc) & 26,2 & $\mathrm{~S} 2$ & 26,2 & S1 & 26,2 & S1 & 26,2 & S1 & 26,2 & S1 & 26,2 & $\mathrm{~S} 1$ \\
\hline $\begin{array}{l}\text { Suhu Tahunan Rata- } \\
\text { rata }\left({ }^{\circ} \mathrm{C}\right) \\
\text { Ketersediaan Air (wa) }\end{array}$ & & & & & & & & & & & & \\
\hline $\begin{array}{l}\text { CurahHujan Tahunan } \\
\text { rata-rata (mm) }\end{array}$ & $\begin{array}{c}209 \\
4\end{array}$ & S1 & 2094 & S1 & 2094 & S1 & 2094 & S1 & 2094 & S1 & 2094 & S1 \\
\hline Jumlah Bulan Kering & 2 & S2 & 2 & S2 & 2 & S1 & 2 & S1 & 2 & S2 & 2 & S1 \\
\hline $\begin{array}{l}\text { Kelembaban Nisbi (\%) } \\
\text { Ketersediaan Oksigen } \\
\text { (oa) }\end{array}$ & 83,8 & S2 & & & 83,8 & S1 & 83,8 & S3 & 83,8 & S2 & 83,8 & S2 \\
\hline Drainase & Baik & S1 & $\begin{array}{l}\text { Agk } \\
\text { baik }\end{array}$ & S1 & Baik & S1 & Baik & S1 & Baik & S1 & Baik & S1 \\
\hline $\begin{array}{l}\text { Keadaan Perakaran } \\
\text { (rc) }\end{array}$ & & & & & & & & & & & & \\
\hline Tekstur Tanah & Sdg & S1 & $\begin{array}{l}\text { Agk } \\
\text { Halus }\end{array}$ & S1 & $\begin{array}{l}\text { Agk } \\
\text { Halus }\end{array}$ & S1 & $\begin{array}{l}\text { Agk } \\
\text { Halus }\end{array}$ & S1 & $\begin{array}{l}\text { Agk } \\
\text { Halus }\end{array}$ & S1 & $\begin{array}{l}\text { Agk } \\
\text { Halus }\end{array}$ & S1 \\
\hline $\begin{array}{l}\text { Kedalaman Tanah }(\mathrm{cm}) \\
\text { Ketersediaan Hara }(\mathbf{n r})\end{array}$ & 78,4 & S1 & 79,9 & $\mathrm{~S} 2$ & 79,9 & S2 & 80 & S2 & 79,9 & S2 & 80 & S2 \\
\hline $\begin{array}{l}\text { Kapasitas Tukar Kation } \\
\text { (KTK) }\end{array}$ & 20,5 & S1 & 20,5 & S1 & & & 20,5 & S1 & 20,5 & S1 & 20,5 & S1 \\
\hline Kejenuhan Basa (\%) & 61,5 & S1 & 61,5 & S1 & 61,5 & S1 & 61,5 & S1 & 61,5 & S1 & 61,5 & S1 \\
\hline $\mathrm{pH} \mathrm{H} \mathrm{H}_{2} \mathrm{O}$ & 6,4 & S1 & 6,4 & S1 & 6,4 & S1 & 6,4 & S1 & 6,4 & S1 & 6,4 & S1 \\
\hline C Organik(\%) & 1 & S2 & 1,0 & $\mathrm{~S} 1$ & 1,0 & S1 & 1,0 & S1 & 1,0 & S1 & 1,0 & S1 \\
\hline Toksisitas (xc) & & & & & & & & & & & & \\
\hline Salinitas (mg/L) & 13,7 & S2 & & & & & 13,7 & S1 & 12,7 & S2 & 13,7 & S2 \\
\hline $\begin{array}{l}\text { Alkalinitas ESP (\%) } \\
\text { Bahaya Erosi (eh) }\end{array}$ & 0,2 & S1 & & & & & & & 0,2 & S1 & 0,2 & S1 \\
\hline Lereng $(\%)$ & 6,8 & S1 & 6,8 & S1 & 6,8 & S1 & 6,8 & S1 & 6,8 & S1 & 6,8 & S1 \\
\hline $\begin{array}{l}\text { Tingkat Bahaya Erosi } \\
\text { Bahaya Banjir (fh) }\end{array}$ & SR & S1 & SR & S1 & SR & S1 & SR & S1 & SR & S1 & SR & S1 \\
\hline $\begin{array}{l}\text { Banjir } \\
\text { Penyiapan Lahan (lp) }\end{array}$ & F0 & S1 & F0 & S1 & F0 & S1 & F0 & S1 & F0 & S1 & F0 & S1 \\
\hline Batuan Permukaan (\%) & 0,6 & S1 & 0,6 & S1 & 0,6 & S1 & 0,6 & S1 & 0,6 & S1 & 0,6 & S1 \\
\hline Singkapan Batuan (\%) & 1,8 & S1 & 1,8 & S1 & 1,8 & S1 & 1,8 & S1 & 1,8 & S1 & 1,8 & S1 \\
\hline
\end{tabular}


Hasil analisis kesesuaian lahan untuk tanaman vanili di Pulau Bacan Kabupaten Halmahera Selatan menunjukkan tanaman vanili masuk dalam kategori cukup sesuai (S2) yang berarti dari sisi kesesuaian lahan tanaman vanili dapat dikembangkan di Pulau Bacan Kabupaten Halmahera Selatan dengan faktor pembatas suhu (tc), ketersediaan air (wa) ketersediaan oksigen (oa), media perakaran (rc), Ketersediaan hara (nr). Untuk tanaman kelapa sawit di Pulau Bacan Kabupaten Halmahera Selatan menunjukkan tanaman kelapa sawit masuk dalam kategori cukup sesuai (S2) berdasarkan faktor pembatas ketersediaan air (wa) dan media perakaran (rc) untuk kedalaman tanah.

Kesesuaian lahan untuk tanaman kelapa di Pulau Bacan Kabupaten Halmahera Selatan menunjukkan tanaman kelapa termasuk dalam kategori kelas kesesuaian lahan cukup sesuai (S2) dan yang menjadi faktor pembatas yaitu media perakaran (rc), Hasil analisa kesesuaian lahan untuk tanaman kakao di Pulau Bacan Kabupaten Halmahera Selatan menunjukkan kesesuaian lahan untuk tanaman kakao termasuk dalam kategori sesuai marginal (S3) dengan faktor pembatasketersediaan air (wa).

Hasil analisa kesesuaian lahan untuk tanaman pala di Pulau Bacan Kabupaten Halmahera Selatan termasuk dalam kategori kelas cukup sesuai (S2) dengan faktor pembatas ketersediaan air (wa), dan media perakaran (rc). Kesesuaian lahan untuk tanaman cengkeh di Pulau Bacan Kabupaten Halmahera Selatan menunjukkan kesesuaian lahan termasuk dalam kategori kelas cukup sesuai (S2) dengan factor pembatas ketersediaan air (wa) dan media perakaran (rc).

\section{Analisa Sosial Ekonomi}

Parameter ekonomi yang dipakai untuk menganalisa kesesuaian/ kelayakan usaha untuk tiap komoditas tanaman perkebunan yaitu NPV (Net Present Value), IRR (Internal Rate of Return) dan BCR (Benefit Cost Ratio), dapat dilihat pada Tabel 3.

Berdasarkan Tabel 3, usaha tani komoditas tersebut layak diusahakan nilai NPV, IRR dan BCR, dapat dijadikan bahan untuk mengklasifikasikan kelas kesesuaian lahan secara ekonomi.

Hasil analisis ekonomi komoditas tanaman vanili, kelapa, pala dan cengkeh yang diusahakan selama 10 tahun sangat sesuai/layak untuk diusahakan di Pulau Bacan Kabupaten Halmahera Selatan ini terlihat dari nilai BRC yang lebih besar dari 1 (satu), dan terendah untuk tanaman kakao, nilai IRR dari seluruh komoditas lebih tinggi dari bunga bank yaitu diatas $15 \%$, artinya sangat layak untuk di kembangkan di Pulau Bacan. Data tanaman kelapa sawit tidak disajikan mengingat tanaman tersebut belum ada atau belum diusahakan di Pulau Bacan Kabupaten Halmahera Selatan.

Usaha tanaman perkebunan seperti kelapa, pala dan cengkeh sudah dibudidayakan oleh masyarakat pulau Bacan secara turun temurun sehingga masyarakat cukup berpengalaman dalam budidaya tanaman tersebut. Untuk tanaman vanili hanya diusahakan oleh sebagian petani yang mana tanaman tersebut sudah ada sebelumnya yang dibawa oleh pemerintah Belanda. Kelapa sawit sama sekali belum diusahakan di Pulau Bacan Kabupaten Halmahera Selatan.

Tabel 3. Indikator Kelayakan Investasi Tanaman Ttahunan (rerata tahun/Ha)

\begin{tabular}{|l|c|c|r|c|c|}
\hline Jenis tanaman & $\begin{array}{c}\text { Periode } \\
\text { Analisis } \\
\text { (tahun) }\end{array}$ & Investasi (Rp/ha) & $\begin{array}{c}\text { NPV (Rp) } \\
(\mathrm{i}=15 \%)\end{array}$ & IRR (\%) & $\begin{array}{c}\text { BCR } \\
(\mathrm{i}=15 \%)\end{array}$ \\
\hline Kelapa & 10 & 10.075 .000 & 4.797 .330 & 34,76 & 1,76 \\
\hline Kakao & 10 & 33.722 .500 & 8.257 .638 & 3476 & 1,45 \\
\hline Cengkeh & 10 & 28.200 .000 & 104.731 .108 & 53,61 & 6,54 \\
\hline Pala & 10 & 17.140 .000 & 15.959 .607 & 43,30 & 2,51 \\
\hline Vanili & 10 & 42.200 .000 & 34.531 .194 & 40,33 & 2,14 \\
\hline
\end{tabular}




\section{KESIMPULAN DAN SARAN}

\section{Kesimpulan}

1. Kesesuaian lahan di Pulau Bacan Kabupaten Halmahera Selatan untuk komoditas perkebunan tanaman vanili, kelapa sawit, kelapa, pala dan cengkeh termasuk dalam kelas kesesuaian lahan cukup sesuai (S2), dengan faktor pembatas paling sedikit pada tanaman kelapa. Kakao termasuk dalam kategori kesesuaian lahan sesuai marginal (S3). Dari segi analisis kelayakan usaha tani komoditas tersebut menunjukan BCR $>1$ artinya sangat layak dikembangkan kecuali tanaman kakao dengan nilai BCR terendah.

2. Tanaman perkebunan yang cocok untuk dikembangkan di Pulau Bacan Kabupaten Halmahera Selatan adalah vanili, kelapa swait, kelapa, pala dan cengkeh pada kelas kesesuaian lahan cukup sesuai (S2) sedangkan kelas kesesuaian lahan untuk tanaman kakao adalah sesuai marginal (S3) tidak direkomendasikan untuk usaha pengembanganya.

\section{Saran}

1. Perlu adanya pemetaan wilayah untuk setiap komoditi perkebunan di Kabupaten Halmahera Selatan berdasarkan potensi kesesuaian lahan.

2. Diperlukan adanya inovasi tekhnologi dalam pengolahan hasil perkebunaan dan dukungan pemerintah Daerah Kabupaten Halmahera Selatan dalam menjaga kestabilan harga komoditi perkebunan.

\section{DAFTAR PUSTAKA}

Anonim. 2011. Petunjuk Teknis Evaluasi Lahan Untuk Komoditas Pertanian. Balai Besar Penelitian Dan Pengembangan Sumberdaya Lahan Pertanian, Balai Penelitian dan Pengembangan Pertanian, Bogor.

Badan Meteorologi dan Geofisika, Stasiun Meteorologi Kelas III Labuha , 2015
Data Curah Hujan, Suhu Dan Kelembaban Periode 2005-2015.

Badan Pusat Statistik Kabupaten Halmahera Selatan 2014.Halmahera Selatan Dalam Angka 2014. Katalog BPS No: 110201.8204

Balai Komoditi Industry, Departemen Pertanian, 2009. Budidaya Tanaman Pala. (Diakses tanggal 11 November 2014) pada situs: http://balitri,litbang.deptan.go.id/databas e/Budidaya\%20pala.pdf

Bayu Pradana, 2013. Analisis Kesesuaian Lahan Pertanian Terhadap Komoditas Pertanian Di kabupaten Cilacap. Jurnal Geodesi Undip Vol 2 no 2. ISSN : 2337-845x

Djaenudin, Marwan H., H.Subagyo., Mulyani, Anny., Suharta, N. 2003. Kriteria Kesesuaian Lahan Untuk Komoditas Pertanian Versi 4. Jakarta. Pusat Penelitian Tanah Dan Agroklimat, Badan Penelitian Dan Pengembangan Pertanian

FAO, 1976. "A Framework For Land Evaluation". Diakses tanggal 5 Nopember 2014:http://www.fao.org/docrep/X5310E/5 $130 \mathrm{e} 00 . \mathrm{htm}$.

Hardjowigeno, Sarwono,1993. Klasifikasi Tanah dan Pedogenesis. Jakarta: CV Akademika Pressindo.

Nasution Z. 2005. Evaluasi Lahan Daerah Tangkapan Hujan Danau Toba Sebagai Dasar Perencanaan Tata Guna Lahan Untuk Pembangunan Berkelanjutan. USU. Medan.

Nazir M. 2009 Metode Penelitian, Penerbit Ghalia, Jakarta.

Delia. Y. 2012. Kesesuaian Lahan Untuk Tanaman Kelapa Sawit Di Kecamatan Semitau Kabupaten Kapuas Hulu. Jurnal Universitas Negeri Jogjakarta Vol. IV 2012. 
Rayes M. Luthfi. 2007. Metode Inventarisasi Sumberdaya Lahan. Yogyakarta: Penerbit Andi.

Ritung S, Wahyunto, Agus F, Hidayat H. 2007. Panduan Evaluasi Kesesuaian Lahan dengan Contoh Peta Arahan Penggunaan Lahan Kabupaten Aceh Barat.Balai Penelitian Tanah dan World Agroforestry Centre (ICRAF), Bogor. Indonesia

Rossister, D.G. and A.R Van Wambeke.1997 ALES (Automated Land Evaluation System), Version 4.6 User"s Manual.SCAS Teaching Series No.T93-2 Revision 6.Cornell University, Departemen of Soil, Crop \& Atmospheric Siences.SCS, Ithaca, New York.

Siregar, Tumpal.H.S, Riyadi.S, Nuraeni Laeli, 2014.Budidaya Cokelat. Cetakan ke- 4. Penerbit Swadaya, Jakarta
Sitorus, Santun. 1985. Evaluasi Sumber Daya Lahan, Penerbit Tarsito, Bandung

Sunarko, 2012.Membangun Kebun Mini Kelapa Sawit Di Lahan 2 Hektar. Jakarta: PT. Agromedia.

Teknologi Unggulan Tanaman Cengkeh, Pusat Penelitian dan Pengembangan perkebunan, (Diakses tanggal 11 Nopember 2014) situs http://balitri,litbang.deptan.go.id/databse/ unggulan/bookletcengkeh.pdf

Teguh Yuono, 2013. Syarat Tumbuh Tanaman Kelapa (Diakses tgl 10 November 2014). Pada situs (http://syarattumbuhtanaman kelapa.com/2013/5/syarat-tumbuhtanaman-kelapa.html 